\title{
Synthesis and characterization of branched polymers by a free radical approach using a novel 'macroiniferter'
}

\author{
Latha Ramakrishnan*, Kannan Sivaprakasam ${ }^{1}$ \\ Department of Inorganic and Physical Chemistry, Indian Institute of Science, Bangalore 560 012, India
}

\begin{abstract}
Free radical bulk polymerization of styrene and methyl methacrylate (MMA) was carried out using a novel 'macroiniferter' which resulted in branched polymers with relatively narrow molecular weight distribution. This approach involving the novel macroiniferter; poly[3-( $t$ butylperoxy)propyl disulfide] (PBPPDS) that has side chain peroxide groups and main chain disulfide linkages was developed to prepare soluble branched polymers as well as to control the extent of branching in vinyl polymers synthesized via a free radical route. The synthesis, characterization and thermal degradation studies of PBPPDS are reported here for the first time. The resulting polystyrene (PS) and poly(methyl methacrylate) (PMMA) polymers were characterized using gel permeation chromatography (GPC), intrinsic viscosity [ $\eta$ ] measurements and the degree of branching was studied by the determination of $g^{\prime}$ factor.
\end{abstract}

Keywords: Macroiniferter; Branched polymer synthesis; Polysulfide polymers

\section{Introduction}

The synthesis of highly branched polymer structures such as dendrimers, stars, and combs has been explored extensively in recent years [1,2]. This current interest in macromolecular architecture is due to the strong influence of the chain structure on the solution and bulk properties of the macromolecules [2-6]. The branched polymers have lower bulk viscosity $(\eta)$ than their linear counterparts and hence it is easy to process them in the molten state. In chain growth polymerization, anionic polymerization has been the widely used approach for synthesizing the branched

\footnotetext{
Abbreviations PS, Polystyrene; PMMA, Poly(methyl methacrylate); MMA, Methyl methacrylate; GPC, Gel permeation chromatography; PBPPDS, Poly[3-(t-butylperoxy) propyl disulfide]; EI-MS, Electron impact-mass spectrum; $[\eta]$, Intrinsic viscosity; SEFT, spin echo fourier transform.

* Corresponding author. Address: 217 Biotechnology Building, Cornell University, Ithaca, NY 14853-2703, USA. Tel.: + 1607255 7169; fax: +1 6072556249 .

E-mail address: 1r52@cornell.edu (L. Ramakrishnan).

${ }^{1}$ Present address: 217 Biotechnology Building, Cornell University, Ithaca, NY 14853-2703, USA.
}

polymers [7-9]. This is because of the ability to control the termination step which is required for making many of the branch architectures. However, commercially most polymers are manufactured using free radical polymerization due to the high cost of monomer purification and the stringent reaction conditions required for ionic polymerization.

Though free radical polymerization is widely used, the synthesis of polymers having controlled structure was considered impossible until recently [1]. The 'living' free radical polymerization by TEMPO mediated and the atom transfer radical polymerization (ATRP) methods have shown that it is possible to synthesize narrow dispersity polymers by the free radical method too [1]. However, the initial significant breakthrough to this problem came by 'iniferter' concept introduced by Otsu [10] in 1982. Vinyl polymers with controlled structures were prepared using this concept employing cyclic disulfide as the iniferter [11].

Different approaches to branching during free radical polymerization include the addition of a small amount of divinyl monomer [12], vinyl functional initiator [13], polyfunctional initiator [14], or vinyl functional chain transfer agent [15] to the polymerization reaction mixture. These approaches, however ultimately would result in gel formation as the polymerization is carried out for extended period of time. A novel approach to eliminate this problem 
relies on incorporation of latent functional groups into the polymer backbone during polymerization [16]. These functional groups are activated later to couple and form branch points during a post polymerization thermolysis [16].

Here, the synthesis of branched vinyl polymers via a macroiniferter approach is discussed. The synthesis of a novel macroiniferter with main chain disulfide and side chain peroxide linkages, namely, poly[3-( $t$-butylperoxy) propyl disulfide] (PBPPDS), is reported for the first time. The structure and energetics of PBPPDS is so designed that in bulk free radical polymerization, the initiation will be through the side chain peroxides, while the main chain disulfide linkages will undergo chain transfer reactions. When the bulk free radical polymerization of vinyl monomers is carried out in the presence of PBPPDS, randomly branched polymers are expected as depicted in the Scheme 2. The initiating and chain transfer ability of peroxide and disulfide linkages, respectively, is well documented [17-19]. Though the chain transfer behavior of low molecular weight polysulfides are well studied [18], the utility of polymeric sulfides were not studied until recently [20]. The polymeric sulfides, namely, poly(styrene disulfide) (PSD) and poly(styrene tetrasulfide) (PST), were proved to be efficient chain transfer agents (CTA's) compared to their low molecular counterparts [20]. In conventional free radical polymerization as the concentration of the initiator increases the rate of polymerization also increases, but the molecular weight decreases. Nontraditional polyfunctional initiators such as vinyl polyperoxides are used to overcome this undesirable effect [21-23]. Further, these are better than the low molecular weight peroxides because of their better control on the molecular weight and polydispersity of the resulting polymers [24].

The studies on the synthesis and characterization of PBPPDS as well as its 'iniferter-like' behavior in the bulk free radical polymerization of styrene and methyl methacrylate (MMA) are reported here. The vinyl polymers thus produced, namely, polystyrene (PS) and poly(methylmethacrylate) (PMMA), are structurally well characterized by intrinsic viscosity $[\eta]$ measurements and gel permeation chromatography (GPC). Extent of branching in these polymers is studied by determining the $g^{\prime}$ factor [25].

\section{Experimental section}

\subsection{Materials}

Styrene and MMA were freed from inhibitor by washing with dilute $\mathrm{NaOH}$ solution and vacuum distilled. Solvents such as chloroform $\left(\mathrm{CHCl}_{3}\right)$, carbontetrachloride $\left(\mathrm{CCl}_{4}\right)$, methanol, benzene, and tetrahydrofuran (THF) were used after distillation. Bromine, $49 \% \mathrm{HBr}$ solution, and $t$-butyl hydroperoxide (70\%) (Fluka) were used as received. Allyl alcohol was purified by distillation. Allyl bromide was prepared from allyl alcohol as reported [26].

\subsection{Characterization}

The ${ }^{1} \mathrm{H}$ NMR spectra, in $\mathrm{CDCl}_{3}$, were recorded on a Bruker ACF-200 MHz spectrometer using tetramethylsilane (TMS) as the internal standard. The ${ }^{13} \mathrm{C}$ NMR spectra in $\mathrm{CDCl}_{3}$ were recorded on an AMX-400 spectrometer operating at $100.6 \mathrm{MHz}$ using TMS as the internal standard. The FTIR spectrum was recorded on a Bruker IFS-55 spectrometer. The UV spectrum of PBPPDS in $\mathrm{CHCl}_{3}$ was recorded on a HITACHI U-3000 spectrophotometer. Thermogravimetric analysis was accomplished on a Perkin-Elmer TGS2 thermogravimetric analyzer at a heating rate of $10{ }^{\circ} \mathrm{C} / \mathrm{min}$. Differential scanning calorimetric (DSC) measurement of the polymer (10-14 mg) was carried out in nitrogen atmosphere using a Perkin-Elmer 7 series thermal analysis system at a heating rate of $2{ }^{\circ} \mathrm{C} / \mathrm{min}$. Electron impact mass spectrum (EI-MS) in the positive mode was obtained at $70 \mathrm{eV}$ using a JEOL JMS-DX 303 mass spectrometer. The sample was introduced by direct inlet probe and it was heated from $25-400{ }^{\circ} \mathrm{C}$ at a heating rate of $64{ }^{\circ} \mathrm{C} / \mathrm{min}$.

The molecular weight (both weight $\left(\bar{M}_{\mathrm{w}}\right)$ average and number-average $\left.\left(\bar{M}_{\mathrm{n}}\right)\right)$ and molar mass distributions $\left(\bar{M}_{\mathrm{w}} /\right.$ $\bar{M}_{\mathrm{n}}$ ) of PS and PMMA samples in THF were measured by GPC with JASCO HPLC pump type PU880, a Varian 5500 apparatus equipped with a refractive index (RI) and multiangle laser light scattering (MALLS) (DAWN-F laser photometer, Wyatt Technology) dual detection. Three TSK gel columns calibrated with PS standards were used. The flow rate of THF (used as an eluent) was $0.7 \mathrm{ml} / \mathrm{min}$. The refractive index increments $(\mathrm{d} n / \mathrm{d} c)$ were $0.183 \mathrm{ml} / \mathrm{g}$ for PS and $0.0870 \mathrm{ml} / \mathrm{g}$ for PMMA. Measurements of $[\eta]$ for PS and PMMA samples were done at $25^{\circ} \mathrm{C}$ in THF using Schott-Gerate viscometer.

\subsection{Monomer synthesis}

\subsubsection{Synthesis of 3-(t-butylperoxy)prop-1-ene}

A mixture of $t$-butyl hydroperoxide $(70 \%)(0.039 \mathrm{~mol})$, $\mathrm{NaOH}(0.042 \mathrm{~mol})$, benzene $(15 \mathrm{ml})$, and tetra- $n$-butylammonium bromide (TBAB) $(0.4 \mathrm{~g})$ were stirred for $15 \mathrm{~min}$ at room temperature. Allyl bromide $(0.039 \mathrm{~mol})$ was then slowly added to the mixture over a period of $30 \mathrm{~min}$ and further stirred at room temperature for $4 \mathrm{~h}$. The reaction mixture was washed several times with water to remove the inorganic salts, and then benzene was removed by vacuum distillation to get 3-(t-butylperoxy)prop-1-ene. The yield, based on allyl bromide, was $85 \%$. ${ }^{1} \mathrm{H} \mathrm{NMR}\left(\mathrm{CDCl}_{3}, \mathrm{TMS}\right)$ : $1.25 \mathrm{ppm}\left(\mathrm{s}, 9 \mathrm{H},-\mathrm{C}\left(\mathrm{CH}_{3}\right)_{3}\right), 4.43 \mathrm{ppm}\left(\mathrm{d}, 2 \mathrm{H},-\mathrm{OOCH}_{2}-\right)$, $5.28\left(\mathrm{dd}, 2 \mathrm{H}, \mathrm{CH}_{2}=\right), 5.93 \mathrm{ppm}\left(\mathrm{m}, 1 \mathrm{H},=\mathrm{CH}-\mathrm{CH}_{2} \mathrm{OO}\right)$.

\subsubsection{Synthesis of t-butyl 2,3-dibromopropyl peroxide}

To a $\mathrm{CCl}_{4}$ solution of 3-(t-butylperoxy)prop-1-ene $(0.0307 \mathrm{~mol})$ cooled in freezing mixture, $\mathrm{Br}_{2}(0.031 \mathrm{~mol})$ in $\mathrm{CCl}_{4}$ was added drop wise for $30 \mathrm{~min}$. After the addition was complete, the reaction mixture was stirred for $2 \mathrm{~h}$ and 
then slowly allowed to attain room temperature. Excess $\mathrm{CCl}_{4}$ was removed using a rotary evaporator and $t$-butyl 2,3dibromopropyl peroxide was purified by vacuum distillation. The yield was $90 \%$ based on 3-( $t$-butylperoxy)prop-1ene. ${ }^{1} \mathrm{H}$ NMR $\left(\mathrm{CDCl}_{3}\right.$, TMS $): 1.25 \mathrm{ppm}\left(\mathrm{s}, 9 \mathrm{H},-\mathrm{C}\left(\mathrm{CH}_{3}\right)_{3}\right)$, $3.63 \mathrm{ppm}\left(\mathrm{d}, 2 \mathrm{H},-\mathrm{CH}_{2} \mathrm{OO}-\right), 4.26 \mathrm{ppm}\left(\mathrm{d}, 2 \mathrm{H}, \mathrm{BrCH}_{2}-\right)$, $4.5 \mathrm{ppm}\left(\mathrm{m}, 1 \mathrm{H},-\mathrm{CH}(\mathrm{Br})-\mathrm{CH}_{2} \mathrm{OO}-\right)$.

\subsection{Polymer synthesis}

\subsubsection{Synthesis of poly(3-(t-butylperoxy)propyl disulfide) (PBPPDS)}

$\mathrm{Na}_{2} \mathrm{~S}_{2}$ was prepared from $\mathrm{Na}_{2} \mathrm{~S} .9 \mathrm{H}_{2} \mathrm{O}(4.8 \mathrm{~mol})$ and sulfur $(4.8 \mathrm{~mol})$ as reported [27]. To a $\mathrm{Na}_{2} \mathrm{~S}_{2}$ solution in water, $t$-butyl 2,3-dibromopropyl peroxide (4 mol) in $\mathrm{CHCl}_{3}$ was added and stirred at room temperature for $24 \mathrm{~h}$ in the presence of the phase transfer catalyst, TBAB. Then the $\mathrm{CHCl}_{3}$ layer was separated, washed with water several times and dried over anhydrous $\mathrm{Na}_{2} \mathrm{SO}_{4}$. The polymer precipitated out when the $\mathrm{CHCl}_{3}$ solution was poured into a large excess of methanol. The polymer was subsequently reprecipitated twice from $\mathrm{CHCl}_{3}$ for purification and then vacuum dried to a constant weight.

\subsubsection{Bulk polymerization of styrene/MMA with PBPPDS}

Bulk free radical polymerization of styrene or MMA (dissolved oxygen in the monomers was removed by flushing nitrogen) in the presence of PBPPDS as macroiniferter was carried out at $100{ }^{\circ} \mathrm{C}$ in evacuated and sealed glass tubes. A typical polymerization of the monomer styrene was carried out by taking $8.74 \mathrm{~mol} / 1(5 \mathrm{ml})$ of styrene in a long glass tube and adding 0.0426 mol equiv./l ( 1 mol equiv. is the weight of the repeat unit of PBPPDS expressed in grams) of the macroiniferter PBPPDS; the long glass tube was flushed for $15 \mathrm{~min}$ with nitrogen to remove the dissolved oxygen in the monomer and then sealed. The polymerization was then carried out at $100{ }^{\circ} \mathrm{C}$ for $180 \mathrm{~min}$. The polymerization tube was then broken and the PS polymer was precipitated and purified from benzene using excess of methanol as non-solvent and dried under vacuum to a constant weight. The PS polymer was repeatedly reprecipitated from $\mathrm{CHCl}_{3}$ solution by methanol and then dried under vacuum before carrying out the GPC analysis (see Table 2 for the GPC data). The resulted PS polymer was characterized using ${ }^{1} \mathrm{H}$ NMR. The ${ }^{1} \mathrm{H}$ NMR spectra, in $\mathrm{CDCl}_{3}$, recorded on a Bruker ACF- $200 \mathrm{MHz}$ spectrometer using tetramethylsilane (TMS) as the internal standard for the PS polymer is shown in Fig. 1(b).

\section{Results and discussion}

\subsection{Synthesis, characterization and thermal degradation studies on PBPPDS}

PBPPDS, a main chain disulfide polymer with pendant

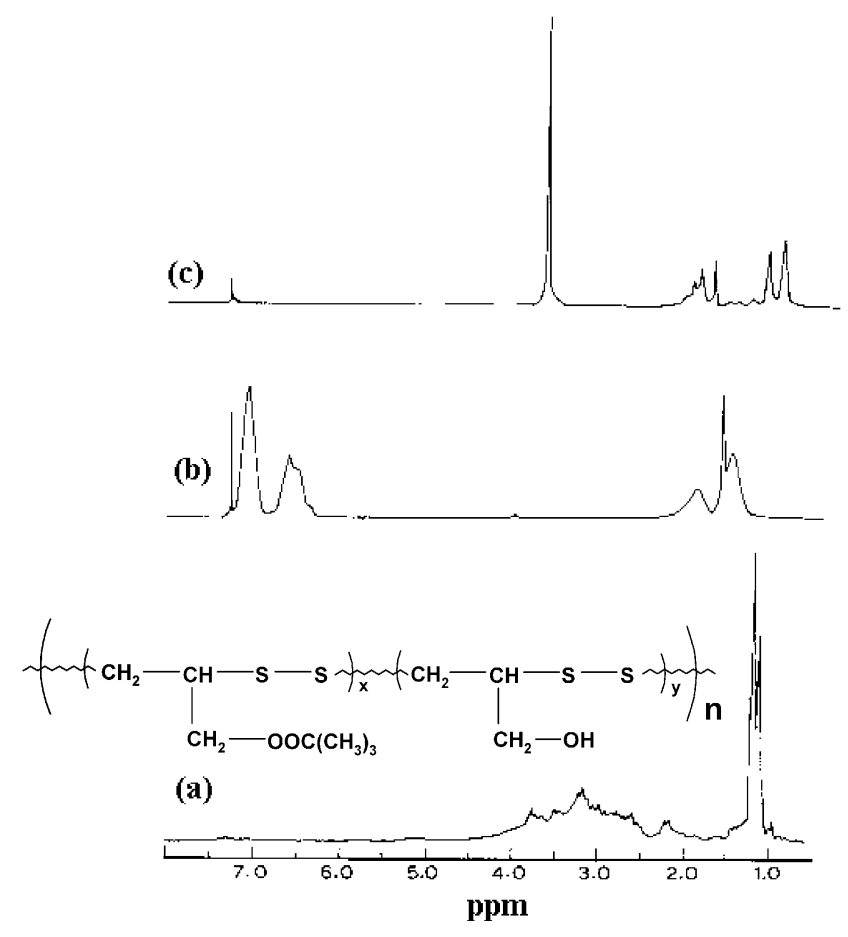

Fig. 1. $200 \mathrm{MHz}{ }^{1} \mathrm{H}$ NMR spectra in $\mathrm{CDCl}_{3}$ of PBPPDS (a), PS (b), and PMMA (c). In the scheme in (a), $x=1$, and $y=1.2$.

peroxy linkages was synthesized by interfacial condensation polymerization as shown in Scheme 1.

The $200 \mathrm{MHz}{ }^{1} \mathrm{H}$ NMR spectrum of PBPPDS is given in Fig. 1(a). The spectrum shows two signals: a broad unresolved signal between 1.8 and $4.4 \mathrm{ppm}$ for the backbone $\mathrm{CH}_{2}, \mathrm{CH}, \mathrm{CH}_{2} \mathrm{OO}$ groups, and another signal at $1.13 \mathrm{ppm}$ corresponding to the $t$-butyl group. There was a deviation from the expected ratio of the intensity of these signals. The intensity of the signal at $1.13 \mathrm{ppm}$ corresponding to the $t$-butyl group was much less than what was expected. This may be due to the base hydrolysis of the peroxide bond in the side chain to the hydroxyl group. During the interfacial polycondensation, sodium polysulfide in the aqueous medium is known to produce sodium hydroxide [28]. The base thus generated cleaves the pendant peroxy linkages to produce hydroxyl groups, thereby reducing the intensity of the $t$-butyl groups in the ${ }^{1} \mathrm{H}$ NMR. The most-likely structure of PBPPDS based on ${ }^{1} \mathrm{H}$ NMR is given in Fig. 1(a). $200 \mathrm{MHz}{ }^{1} \mathrm{H}$ NMR of PS and PMMA obtained by bulk free radical polymerization with PBPPDS as depicted in Scheme 2 is shown in Fig. 1(b) and (c), respectively.

The broad band decoupled ${ }^{13} \mathrm{C}$ NMR spectrum of PBPPDS recorded in $\mathrm{CDCl}_{3}$ is shown in Fig. 2(a) and the signal at $28 \mathrm{ppm}$ corresponds to the $\mathrm{CH}_{3}$ carbon of the $t$-butyl group. Apart from this well-defined signal, there are broad poorly resolved signals between 30 and $70 \mathrm{ppm}$.

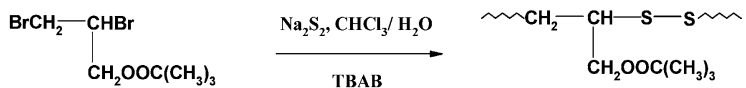

Scheme 1. Synthesis of PBPPDS. 


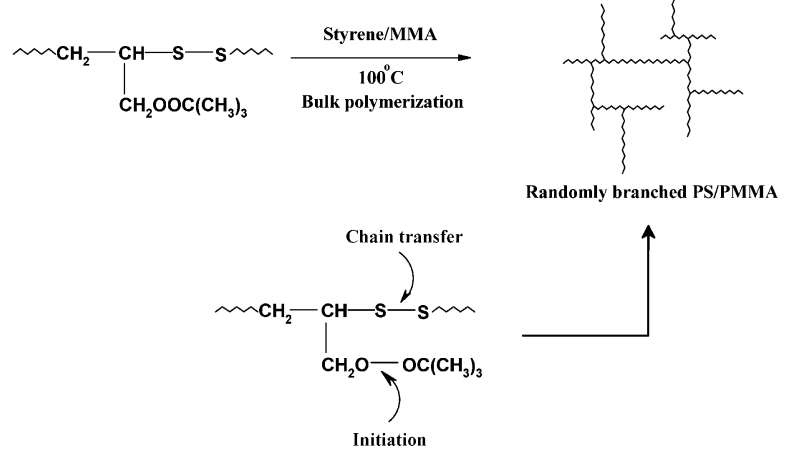

Scheme 2. Polymerization of vinyl monomers with PBPPDS.

Based on the SEFT ${ }^{13} \mathrm{C}$ NMR spectrum (Fig. 2(b)), the signals in the region $32-45 \mathrm{ppm}$ were assigned to the backbone $\mathrm{CH}_{2}$ carbon. The signals between 45 and $60 \mathrm{ppm}$ were assigned to backbone methine carbon and the signal at $64 \mathrm{ppm}$ is due to the methylene carbon bonded to the peroxide. The quaternary carbon of the $t$-butyl group resonates at $75.2 \mathrm{ppm}$.

The FTIR spectrum of a neat film of PBPPDS (Fig. 3(a)) shows a strong band near $1044 \mathrm{~cm}^{-1}$ due to the stretching vibration of the peroxide $(\mathrm{O}-\mathrm{O})$ group. The broad band appearing at $3400 \mathrm{~cm}^{-1}$ is assigned to the stretching of the hydroxyl group. The high intensity of this band supports the observation made from the ${ }^{1} \mathrm{H}$ NMR spectra of PBPPDS
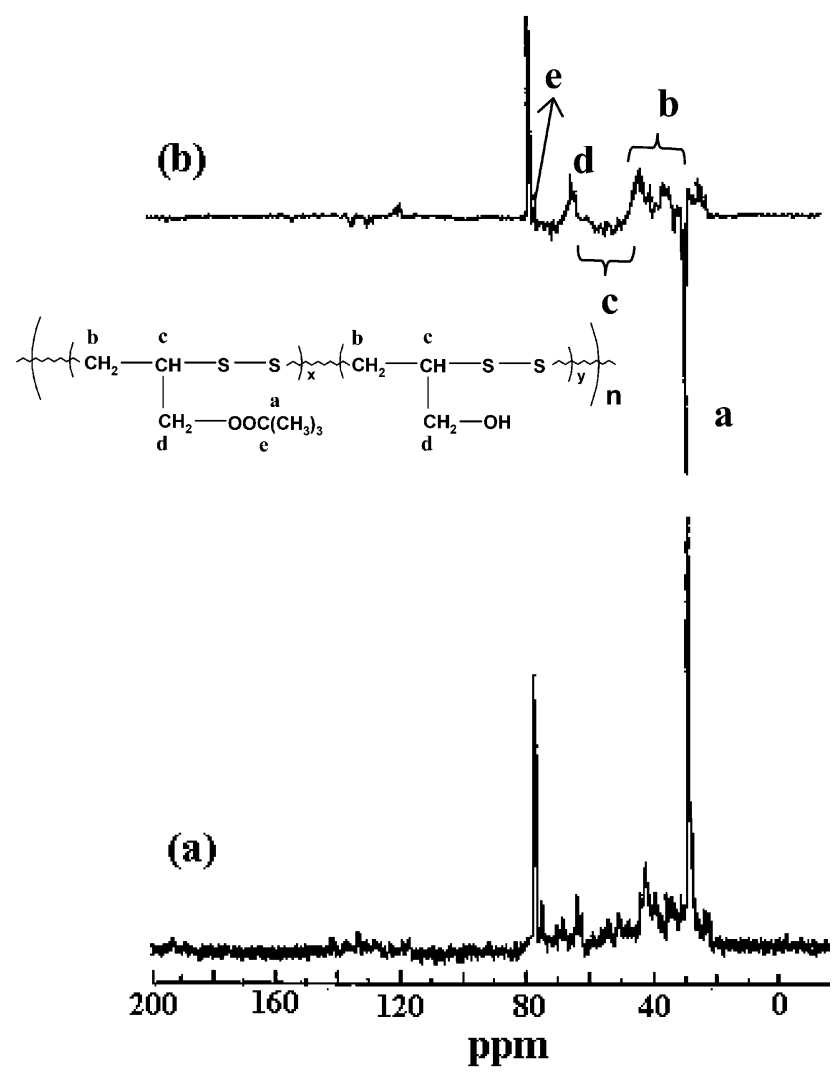

Fig. 2. $100.6 \mathrm{MHz}{ }^{13} \mathrm{C}$ spectra in $\mathrm{CDCl}_{3}$ of PBPPDS: ${ }^{1} \mathrm{H}$ decoupled (a, bottom) and SEFT (b, top).
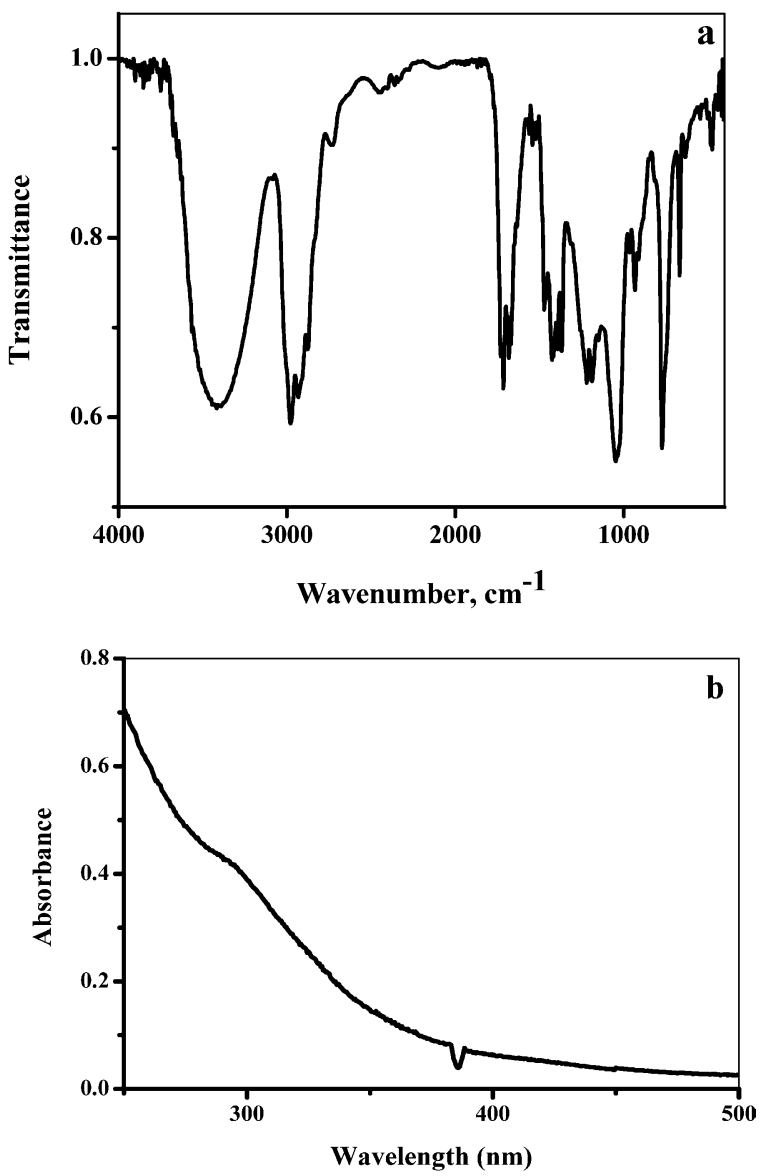

Fig. 3. FTIR spectrum of PBPPDS film (a, top) and UV absorption spectrum of PBPPDS in $\mathrm{CHCl}_{3}$ (b, bottom).

regarding the presence of pendant hydroxyl groups in the macroiniferter. The aliphatic $\mathrm{C}-\mathrm{H}$ stretching bands of this polymer appear in the region $2980-2880 \mathrm{~cm}^{-1}$. In the finger print region, the band at $1190 \mathrm{~cm}^{-1}$ was assigned to the stretching vibration of the $\mathrm{C}-\mathrm{O}$ bond of the peroxide linkage. Since the $\mathrm{C}-\mathrm{S}$ and $\mathrm{S}-\mathrm{S}$ vibrations are generally weak, they were not identified in the FTIR spectrum of PBPPDS.

The Fig. 3(b) presents the UV spectrum of PBPPDS recorded in $\mathrm{CHCl}_{3}$. Most of the aliphatic disulfides show UV absorption due to the conjugation of lone pair of electrons on the sulfur atoms [29]. Molecular orbital treatment led to the conclusion that the UV absorption band is associated with an electronic transition from the antibonding $\pi$ orbital (formed by the combination of $3 p \pi$ atomic orbital) to the antibonding $\sigma$ orbital [29]. For PBPPDS, the shoulder band around $280 \mathrm{~nm}$ is assigned to the $\mathrm{S}-\mathrm{S}$ linkages present in the backbone of the polymer.

The thermogravimetric (TG) curve of PBPPDS is shown in Fig. 4(a). It shows a weight loss from 100 to $350{ }^{\circ} \mathrm{C}$. Between the peroxide $(\mathrm{O}-\mathrm{O})$ and disulfide $(\mathrm{S}-\mathrm{S})$ linkages, the peroxide linkages are thermally more labile than the latter. The thermal stability of the polyperoxide and polysulfide polymers has been studied extensively [28]. It 

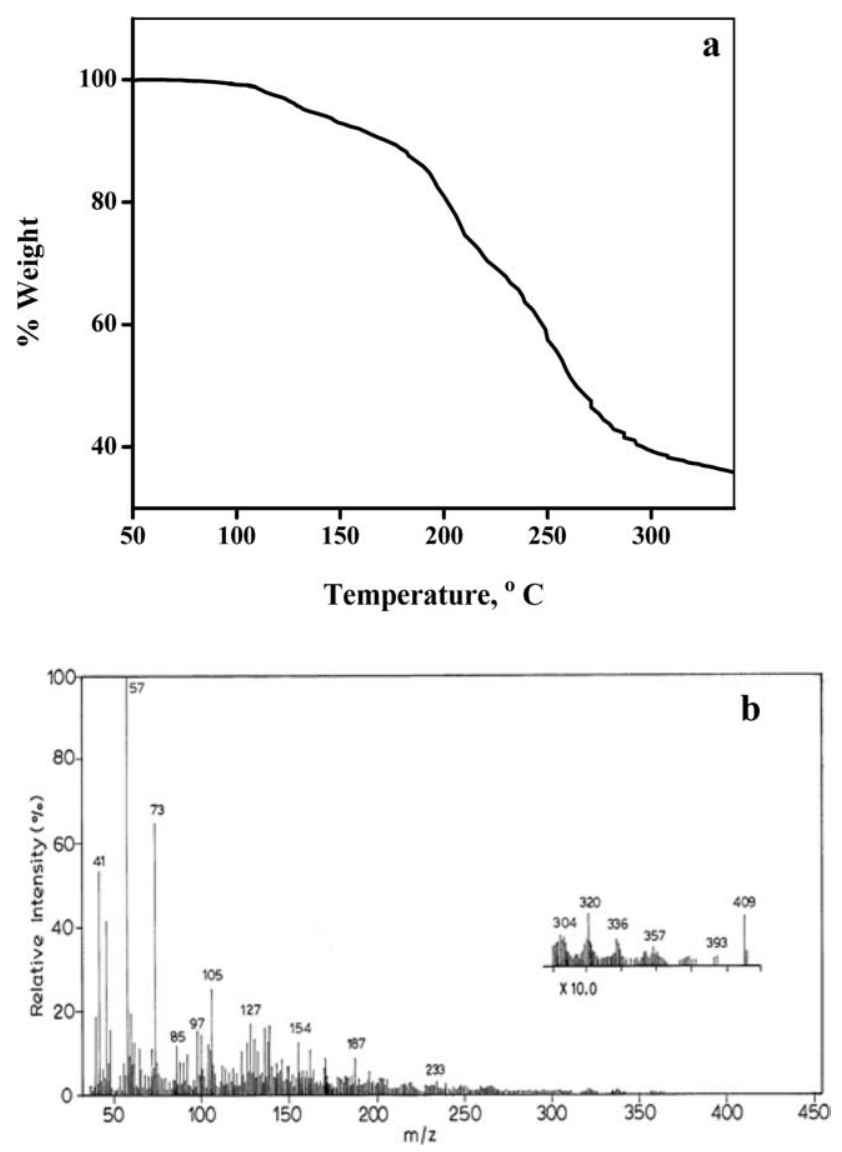

Fig. 4. TGA trace of PBPPDS (a, top) and EI-MS of PBPPDS at $70 \mathrm{eV}$ (b, bottom).

has been observed that the onset of degradation in a polysulfide polymer occurs at a higher temperature than in a polyperoxide polymer [27]. The first weight loss between $100^{\circ}$ and $210^{\circ} \mathrm{C}$ is due to the thermal degradation of the pendant peroxide bonds and the second step of degradation from $210-350{ }^{\circ} \mathrm{C}$ corresponds to the degradation of the main chain disulfide linkages.

The EI-MS of PBPPDS, recorded at $70 \mathrm{eV}$, is presented in Fig. 4(b). The advantages of direct pyrolysis mass spectrometry (DP-MS) in identifying the primary pyrolysis products to obtain information about the most thermally labile bonds in polymers have been established [30]. In addition, in polysulfide polymers, the DP-MS technique has been proved to be useful in understanding the microstructure of the polymer in terms of the 'rank' (which is the average number of sulfur atoms in a polysulfide linkage which is two for a disulfide linkage) of the polysulfide linkages [31]. The primary pyrolysis products identified are at $m / z 130$ and 194 whose structures along with that of the other molecular ions detected in the EI-MS are given in Table 1. The mechanism of formation of the secondary degradation products is discussed in Scheme 3. Since the peroxide bond is thermally more labile than the disulfide bond, the cleavage of the pendant peroxide bond occurs first. Either $\mathrm{O}-\mathrm{O}$ or $\mathrm{C}-\mathrm{O}$ cleaves to form the hydroxyl and

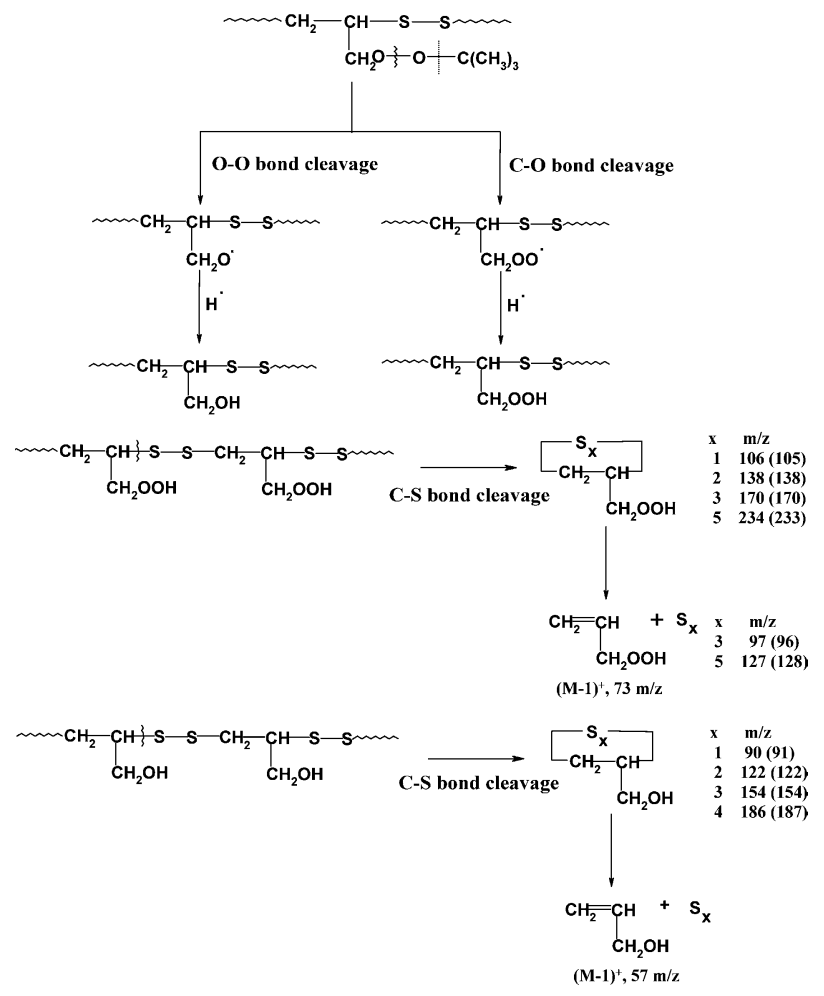

Scheme 3. Thermal degradation mechanism of PBPPDS.

the hydroperoxyl groups, respectively [23]. The C-S bond is known to be less stable than the $\mathrm{S}-\mathrm{S}$ bond in a disulfide [27] and hence the formation of two kinds of cyclic products could be explained by considering the cleavage of the $\mathrm{C}-\mathrm{S}$ bond (Scheme 3).

Some of the cyclic products identified in the EI-MS are reported in Table 1. The less intense molecular ions at $\mathrm{m} / \mathrm{z}$ 409 and 393 reveal the presence of minor levels of monosulfide linkages. The formation of the cyclic product observed at $\mathrm{m} / \mathrm{z} 233$ as a weak intensity signal could be explained only by considering the presence of very few trisulfide linkages in the backbone of the polymer. The presence of minor levels of mono and trisulfide linkages in PBPPDS apart from the major disulfide linkages is due to the mode of synthesis [32]

\subsection{Bulk free radical polymerization of styrene/MMA in the presence of PBPPDS}

In order to study the role of PBPPDS as a macroiniferter, bulk free radical polymerization (at $100{ }^{\circ} \mathrm{C}$ ) of vinyl monomers such as styrene and MMA was carried out in the presence of the macroiniferter. Polymerization was carried out at a higher temperature because of the high thermal stability of the side chain peroxide bonds [23]. Conversion versus time plots for the bulk polymerization of styrene and MMA in the presence of PBPPDS are given in Fig. 5. In both the monomers, the conversion increases with time. The effect of the molecular weight of PS and PMMA 
Table 1

Primary degradation products observed in the EI-MS of PBPPDS

\begin{tabular}{|c|c|}
\hline $\mathrm{m} / \mathrm{z}$ & Compounds \\
\hline $41^{\mathrm{a}}$ & $\mathrm{CH}_{2}=\mathrm{C}=\mathrm{CH}_{2}$ \\
\hline $46^{\mathrm{b}}$ & $\mathrm{CH}_{2} \mathrm{~S}$ \\
\hline $58^{\mathrm{b}}$ & $\mathrm{CH}_{2}=\mathrm{H}-\mathrm{CH}_{2}-\mathrm{OH}$ \\
\hline 62 & $\mathrm{~S}_{2}$ \\
\hline $74^{\mathrm{b}}$ & $\mathrm{CH}_{2}=\underset{\mathrm{H}}{\mathrm{C}}-\mathrm{CH}_{2}-\mathrm{OOH}$ \\
\hline $90^{\mathrm{b}}$ & $\stackrel{\mathrm{S}}{\mathrm{CH}_{2} \mathrm{OH}}$ \\
\hline $96^{\mathrm{a}}$ & $\mathbf{s}_{3}$ \\
\hline $106^{\mathrm{b}}$ & $\stackrel{\mathrm{S}}{\mathrm{CH}_{2} \mathrm{OOH}}$ \\
\hline 122 & $\mathrm{CH}_{2} \mathrm{OH}$ \\
\hline $128^{\mathrm{b}}$ & $\mathrm{S}_{4}$ \\
\hline $130^{\mathrm{b}}$ & $\begin{aligned} \mathrm{CH}_{2}= & \mathrm{CH} \\
& \mathrm{CH}_{2} \mathrm{OOC}\left(\mathrm{CH}_{3}\right)_{3}\end{aligned}$ \\
\hline 138 & $\mathrm{CH}_{\mathrm{C}}^{\mathrm{S}} \mathrm{OOH}$ \\
\hline 154 & \\
\hline 170 & $-\mathrm{CH}_{2} \mathrm{OOH}$ \\
\hline $186^{\mathrm{a}}$ & $\mathrm{CH}_{2} \mathrm{OH}$ \\
\hline $194^{\mathrm{b}}$ & $\int_{\mathrm{CH}_{2} \mathrm{OOC}\left(\mathrm{CH}_{3}\right)_{3}}$ \\
\hline $234^{\mathrm{b}}$ & 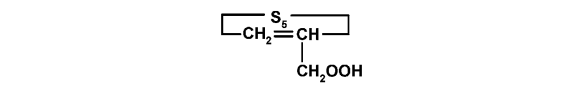 \\
\hline 304 & $\begin{array}{ccc}\mathrm{CH}_{2}-\mathrm{CH}-\mathrm{s}-\mathrm{s}-\mathrm{CH}_{2}-\underset{\mathrm{CH}}{\mathrm{CH}}-\mathrm{s}-\mathrm{s}-\mathrm{CH}_{2}-\mathrm{CH} \\
\mathrm{CH}_{2} \mathrm{OH} & \mathrm{CH}_{2} \mathrm{OH} & \mathrm{CH}_{2} \mathrm{OH}\end{array}$ \\
\hline 320 & \begin{tabular}{cccc|}
$\mathrm{CH}_{2}-\mathrm{CH}-\mathrm{s}-\mathrm{s}-\mathrm{CH}_{2}-\mathrm{CH}_{\mathrm{CH}}-\mathrm{S}-\mathrm{S}-\mathrm{CH}_{2}-\mathrm{CH}$ \\
$\mathrm{CH}_{2} \mathrm{OOH}$ & $\mathrm{CH}_{2} \mathrm{OH}$
\end{tabular} \\
\hline 336 & \begin{tabular}{cccc|}
$\mathrm{CH}_{2}-\underset{\mathrm{CH}}{\mathrm{CH}}-\mathrm{s}-\mathrm{s}-\mathrm{CH}_{2}-\mathrm{CH}_{\mathrm{CH}}-\mathrm{s}-\mathrm{s}-\mathrm{CH}_{2}-\mathrm{CH}$ \\
$\mathrm{CH}_{2} \mathrm{OOH}$ & $\mathrm{CH}_{2} \mathrm{OOH}$ & $\mathrm{CH}_{2} \mathrm{OH}$
\end{tabular} \\
\hline $392^{\mathrm{a}}$ & 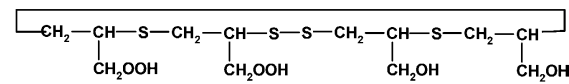 \\
\hline $408^{\mathrm{a}}$ & 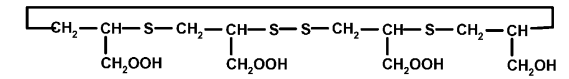 \\
\hline
\end{tabular}

${ }^{\text {a }}$ Observed as $(\mathrm{MH})^{+}$peak in the EI-MS.

${ }^{\mathrm{b}}$ Observed as $(\mathrm{M}-1)^{+}$peak.

on the conversion could be understood from Fig. 6. The plot of $\left(\bar{M}_{\mathrm{n}}\right)$ for both PS and PMMA, prepared using PBPPDS as macroiniferter ( $0.02 \mathrm{~mol}$ equiv./l), against conversion (Fig. 6) shows an increase in $\left(\bar{M}_{\mathrm{n}}\right)$ as \% of conversion increases. In free radical polymerization in the presence of

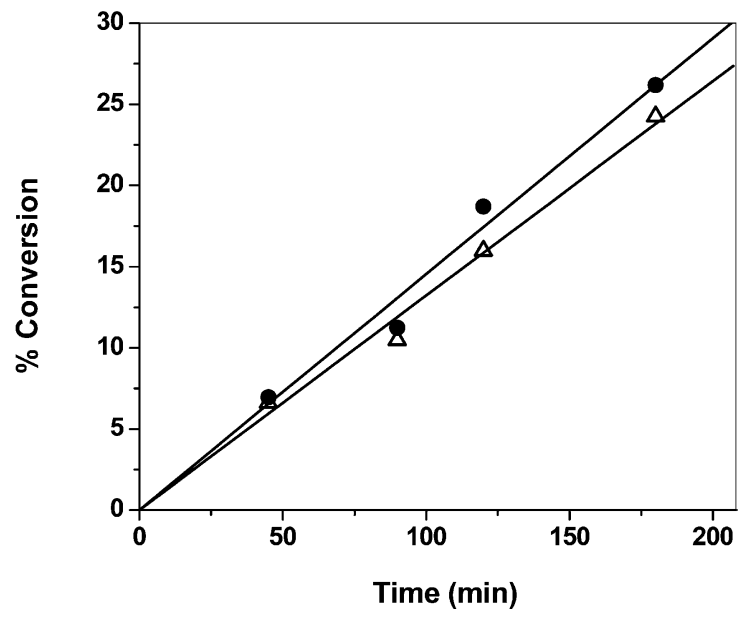

Fig. 5. Conversion-time plot for the bulk polymerization of ( $)$ styrene and $(\triangle) \mathrm{MMA}$ at $100{ }^{\circ} \mathrm{C}$ in the presence of PBPPDS; [PBPPDS] $=$ 0.02 mol equiv./l.

polyfunctional initiators, the molecular weight increases with conversion due to polymerization-recombination mechanism [24]. Such a process is also reported to bring about narrowing of the polydispersity $\left(\bar{M}_{\mathrm{w}} / \bar{M}_{\mathrm{n}}\right)$. The plot of $\left(\bar{M}_{\mathrm{w}} / \bar{M}_{\mathrm{n}}\right)$ as a function of conversion shown in Fig. 6 indeed confirms the narrow polydispersity of these PS and PMMA polymers.

The effect of the concentration of PBPPDS on the conversion and $\left(\bar{M}_{\mathrm{n}}\right)$ is presented in Fig. 7. As [PBPPDS] increases, the conversion increases while the molecular weight decreases. The increase in conversion is because PBPPDS is a polyfunctional initiator, while the chain transfer of the growing polymer chain to the main chain disulfide linkages leads to a decrease in the $\left(\bar{M}_{\mathrm{n}}\right)$.

The PS and PMMA synthesized using PBPPDS ( 0.2 mol equiv./l) as a macroiniferter are characterized by ${ }^{1} \mathrm{H}$ NMR and the spectra are given in Fig. 1(b) and (c), respectively. There may be residual segments of PBPPDS present in these polymers, but the signals corresponding to

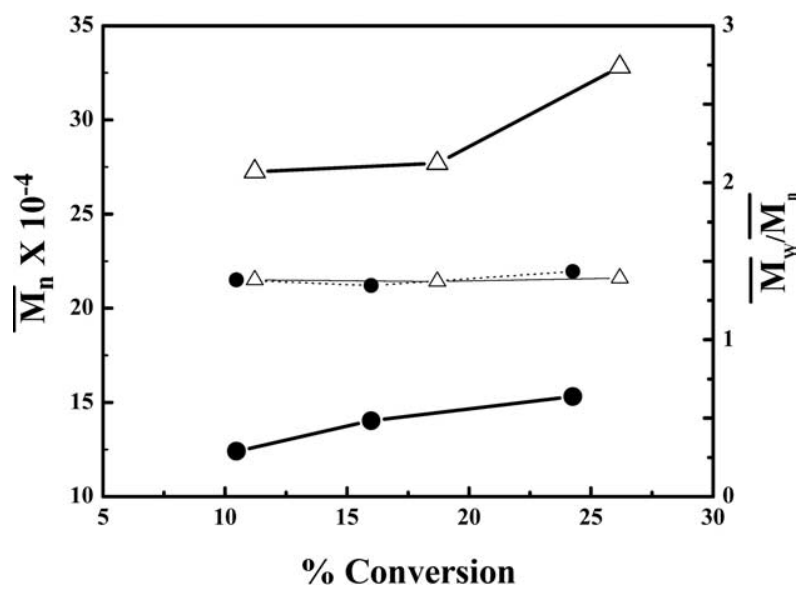

Fig. 6. Plot of $\left(\bar{M}_{\mathrm{n}}\right)$ (solid line) and polydispersity (dashed line) versus conversion of PS $(-)$ and PMMA $(\triangle)$ prepared in the presence of PBPPDS (0.02 mol equiv./l) at $100{ }^{\circ} \mathrm{C}$. 


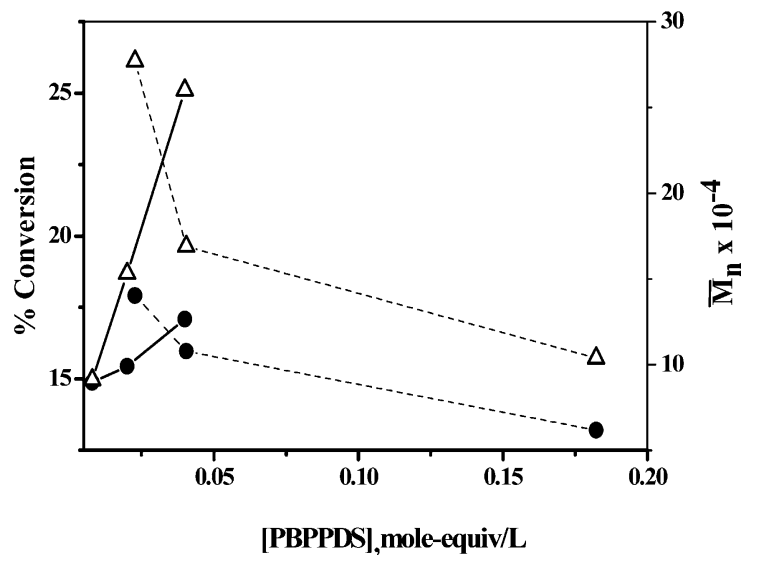

Fig. 7. Plot of conversion (solid line) and $\bar{M}_{\mathrm{n}}$ (dashed line) versus [PBPPDS] of PS $(\bullet)$ and PMMA $(\triangle)$ prepared in the presence of PBPPDS at $100{ }^{\circ} \mathrm{C}$.

them are not observed in the ${ }^{1} \mathrm{H}$ NMR due to the very high molecular weight of PS and PMMA $\left(\left(\bar{M}_{\mathrm{w}}\right)\right.$ is reported in Table 2).

\subsection{Branching}

As described in Scheme 2, the free radical polymerization of styrene and MMA in the presence of PBPPDS is expected to yield randomly branched polymers. However, the presence of branching in the resulting polymers needs to be examined. Branched polymers generally have higher chain segment density, smaller radii of gyration, and lower hydrodynamic volumes compared to linear polymers with the same composition and molecular weight $[33,34]$. These differences are manifested in lower intrinsic viscosity and longer retention volumes by GPC analysis. The most important means of characterizing the extent of branching is through the measurement of dilute solution properties. The classical measure of branching is the Zimm-Stockmayer [35] ratio of the radius of gyration of the branched polymer to that of the linear polymer at the same molecular weight. Estimation of branching is determined from the intrinsic viscosity ratio $[25] g^{\prime}$, as defined in Eq. (1)

$g^{\prime}=\frac{[\eta]_{\mathrm{b}}}{[\eta]_{1}}$

$[\eta]_{\mathrm{b}}$, intrinsic viscosity of the branched polymer; $[\eta]_{1}$, intrinsic viscosity of the corresponding linear polymer.

In addition to $[\eta]$ of the sample, its $\left(\bar{M}_{\mathrm{v}}\right)$ (viscosityaverage molecular weight) must also be known, so that the denominator in Eq. (1) can be calculated. In general, the light scattering technique is used for this, assuming that $\left(\bar{M}_{\mathrm{w}}\right)=\left(\bar{M}_{\mathrm{v}}\right)$. For PS, $[\eta]_{1}=1.314 \times 10^{-2}\left(\bar{M}_{\mathrm{w}}\right)^{0.714} \mathrm{ml} / \mathrm{g}$ (in THF, $25^{\circ} \mathrm{C}$ ) [36] and for PMMA $[\eta]_{1}=1.10 \times 10^{-2}$ $\left(\bar{M}_{\mathrm{w}}\right)^{0.725} \mathrm{ml} / \mathrm{g}$ (in THF, $25^{\circ} \mathrm{C}$ ) [37].

The $g^{\prime}$ values calculated for PS and PMMA polymers are given in Table 2. The $g^{\prime}$ values less than unity indicates that these polymers are all branched. Further, as the concentration of PBPPDS increases, $g^{\prime}$ decreases suggesting that as the concentration of the branching center increases, the degree of branching also increases.

\section{Conclusions}

A novel macroinifeter, PBPPDS, with main chain disulfide and side chain peroxide linkages was synthesized by an interfacial polycondensation route and was characterized using various spectroscopic techniques. The ${ }^{1} \mathrm{H}$ NMR studies indicate the presence of pendant hydroxyl groups in PBPPDS formed by the base hydrolysis of the peroxide bonds, while FTIR studies confirmed their

Table 2

Molecular weight and dilute solution properties of PS and PMMA samples prepared by bulk free radical polymerization in the presence of the macroiniferter, PBPPDS at $100^{\circ} \mathrm{C}$

\begin{tabular}{|c|c|c|c|c|c|c|}
\hline Sample code & {$[\mathrm{M}]^{\mathrm{a} /[\mathrm{PBPPDS}]}$} & $10^{-5} \times\left(\bar{M}_{\mathrm{w}}\right)^{\mathrm{b}}(\mathrm{g} / \mathrm{mol})$ & $\left(\bar{M}_{\mathrm{w}} / \bar{M}_{\mathrm{n}}\right)^{\mathrm{b}}$ & {$[\eta]_{\mathrm{b}}^{\mathrm{c}}(\mathrm{ml} / \mathrm{g})$} & {$[\eta]_{1}(\mathrm{ml} / \mathrm{g})$} & $g^{\prime \mathrm{d}}$ \\
\hline \multicolumn{7}{|l|}{ PS samples } \\
\hline $\mathrm{PSI}_{1}-1$ & 410 & 1.71 & 1.38 & 68.40 & 71.67 & 0.95 \\
\hline $\mathrm{PSI}_{1}-2$ & 410 & 1.88 & 1.34 & 72.10 & 76.79 & 0.94 \\
\hline $\mathrm{PSI}_{1}-3$ & 410 & 2.19 & 1.43 & 83.20 & 85.61 & 0.97 \\
\hline $\mathrm{PSI}_{2}$ & 205 & 1.55 & 1.44 & 61.80 & 67.00 & 0.92 \\
\hline $\mathrm{PSI}_{3}$ & 137 & 1.12 & 1.42 & 43.40 & 52.97 & 0.82 \\
\hline $\mathrm{PSI}_{4}$ & 41 & 1.05 & 1.70 & 39.20 & 50.62 & 0.77 \\
\hline \multicolumn{7}{|c|}{ PMMA samples } \\
\hline $\mathrm{PMI}_{1}-1$ & 410 & 3.76 & 1.38 & 86.25 & 121.27 & 0.71 \\
\hline $\mathrm{PMI}_{1}-2$ & 410 & 3.79 & 1.37 & 92.90 & 122.04 & 0.76 \\
\hline $\mathrm{PMI}_{1}-3$ & 410 & 4.56 & 1.39 & 98.00 & 139.45 & 0.70 \\
\hline $\mathrm{PMI}_{2}$ & 205 & 2.28 & 1.35 & 61.80 & 84.37 & 0.73 \\
\hline $\mathrm{PMI}_{3}$ & 137 & 1.68 & 1.38 & 49.75 & 67.80 & 0.73 \\
\hline $\mathrm{PMI}_{4}$ & 41 & 1.38 & 1.33 & 40.40 & 58.86 & 0.69 \\
\hline
\end{tabular}

\footnotetext{
${ }^{a}[\mathrm{M}]$, where $\mathrm{M}$ is styrene or MMA.

b Determined by GPC using light scattering detectors in THF (at $633 \mathrm{~nm}, 25^{\circ} \mathrm{C}$ ).

c Measured in THF at $25^{\circ} \mathrm{C}$.

${ }^{\mathrm{d}}$ Calculated using Eq. (1).
} 
presence. The thermal degradation studies by DP-MS reveal the presence some mono and trisulfide linkages along with the major disulfide linkages in the backbone of PBPPDS. Bulk free radical polymerization of styrene and MMA in the presence of PBPPDS showed an increase in conversion with time as well as an increase in molecular weight with conversion, a characteristic feature of a polyfunctional initiator in free radical polymerization. The chain transfer reactions of the main chain disulfide linkages lead to a decrease in the molecular weight with an increase in the concentration of PBPPDS, indicating that it acts both as an initiator and a chain transfer agent, hence as a macroiniferter, in free radical polymerization. Finally, both PS and PMMA prepared using PBPPDS by a free radical method were shown to be branched polymers based on their $g^{\prime}$ values (Table 2) and polymerization up to a period of $3 \mathrm{~h}$ yielded soluble branched polymers. The extent of branching can be controlled by varying the concentration of PBPPDS as displayed in Table 2.

\section{Acknowledgements}

The authors would like to dedicate this article to the fond memory of late Professor K. Kishore. LR is grateful to Professor D.N. Sathyanarayana for his guidance during the course of this investigation. KS gratefully acknowledges Professor Yves Gnanou (ENSCPB, University of Bordeaux, France) for allowing him to use the GPC facility.

\section{References}

[1] Malmstrom EE, Hawker CJ. Macromol Chem Phys 1998;199:923.

[2] Ito K, Kawaguchi S. Adv Polym Sci 1999;142:129.

[3] Burchard W. Adv Polym Sci 1999;143:113.

[4] Hempenius MA, Zoetelief WF, Gauthier M, Martin M. Macromolecules 1998;31:2299.

[5] Small PA. Chem Ind 1965;24:1023.

[6] Zimm BH, Kilb RW. J Polym Sci 1959;(37):19.

[7] Hsieh HL, Quirk RP. In: Hudgin DE, editor. Anionic polymerization principles and practical applications. New York: Marcel Dekker; 1996.
[8] Rempp PF, Lutz PJ. In: Eastmond GC, Ledwith A, Russo S, Sigwalt P, editors. Comprehensive polymer science, 6, polymer reactions. Elmsford, NY: Pergamon Press; 1989. p. 403.

[9] Quirk RP, Tsai Y. Macromolecules 1998;31:8016.

[10] Otsu T, Yoshida M, Tazaki T. Makromol Chem Rapid Commun 1982; 3:133.

[11] Otsu T, Yoshida M. Makromol Chem Rapid Commun 1982;3:127.

[12] Zhu S, Hamielec AE. Macromolecules 1993;26:3131.

[13] Matsubara T, Ito N, Ishida Y, Iwamoto M. US Patent 4376847; 1983.

[14] Okumura R, Izumida K. US Patent 5191040; 1993.

[15] Tung LH, Hu AT, McKinley SV, Paul AM. J Polym Sci, Part A: Polym Chem 1981;19:2027.

[16] Delassus SL, Howell BA, Cummings CJ, Dais VA, Nelson RM, Priddy DB. Macromolecules 1994;27:1307.

[17] Pierson RM, Costanza AJ, Weinstein AH. J Polym Sci 1955;17:221.

[18] Pryor WA, Pickering TL. J Am Chem Soc 1962;84:2705.

[19] Sugimura T, Ogata Y, Minoura Y. J Polym Sci, Part A: Polym Chem 1966;4:2747.

[20] Murthy KS, Ganesh K, Kishore K. Polymer 1996;37:5541.

[21] Mukundan T, Bhanu VA, Kishore K. J Chem Soc, Chem Commun 1989;12:780.

[22] Murthy KS, Kishore K. Krishna Mohan V. Macromolecules 1994;27: 7109.

[23] Murthy KS, Kishore K. Macromolecules 1996;29:4859.

[24] Kuchanov SI. Usp Khim 1991;60:1346. Chem Abstr 1991; 115: 208631g.

[25] Yamakawa H. Modern theory of polymer solutions. New York: Harper and Row; 1971. p. 318

[26] Vogel AI. A text-book of practical organic chemistry. London: English Language Book Society; 1972.

[27] Kishore K, Ganesh K. Macromolecules 1993;26:4700.

[28] Kishore K, Ganesh K. Adv Polym Sci 1995;121:81.

[29] Field L. Disulfides and polysulfides. In: Oae S, editor. Organic chemistry of sulfur. New York: Plenum Press; 1977. p. 303

[30] Foti S, Montaudo G. In: Bark LS, Allen NS, editors. Analysis of polymer systems. London: Applied Science; 1982. p. 103.

[31] Ganesh K. PhD Thesis, Indian Institute of Science, Bangalore; 1993.

[32] Tobolsky AV, editor. The chemistry of sulfides. New York: WileyInterscience Publishers; 1968.

[33] Vanbeylen M, Bywater S, Smets G, Szwarc M, Worsfold DJ. Adv Polym Sci 1988;86:87.

[34] Roovers J. In: Kroschwitz JI, editor. Branched polymers. 2nd ed Encyclopedia of polymer science and engineering, 2nd ed, vol. 2, 1985. p. 478.

[35] Zimm BH, Stockmayer WH. J Chem Phy 1949;17:1301.

[36] Meyerhoff G, Appelt B. Macromolecules 1979;12:968.

[37] Spatorico AL, Coulter B. J Polym Sci, Part B: Polym Phys 1973;11: 1139. 